\title{
La antropología como disciplina científica, dimensión biológica y cultural en la naturaleza humana
}

\author{
Anthropology as a scientific discipline, \\ biological and cultural dimension in human nature
}

William Oswaldo Aparicio Gómez ${ }^{1}$
$E d \& T I C$

Recibido: 20.07.2021

Aceptado: 15.09.2021

\section{Resumen}

El campo de intereses de la Antropología es basto. Cubre todas las épocas, todos los espacios, incorporando en las últimas décadas estudios en sociedades complejas, antropología política, económica, estudios de parentesco, etc. Cubre tanto la dimensión biológica -estudio de hominización, clasificación de las variedades raciales- como la dimensión cultural. Pretende explicar tanto las diferencias como las semejanzas entre los distintos grupos humanos. Pretende dar, también, razón tanto de la continuidad como del cambio de las sociedades. Algunos quieren ver las variaciones de las sociedades y las culturas como una evolución semejante a la de las especies. Cuando la biología pretende responder todas las preguntas que el hombre se formula desde una teoría general de los viviente se transforma en una ciencia universal, proponiendo que los comportamientos de los social pasen a lo biológico, algo que hay que criticar.

\footnotetext{
${ }^{1}$ waparicio@editic.net https://orcid.org/0000-0002-8178-1253
} 
Palabras clave: Ciencias de la Educación, Filosofía, Ética, Antropología, Naturaleza humana, Ontología, Humanismo.

\begin{abstract}
The field of interests of Anthropology is vast. It covers all periods, all spaces, incorporating studies in complex societies, political and economic anthropology, kinship studies, etc. in recent decades. It covers both the biological dimension - hominization study, classification of racial varieties - and the cultural dimension. It aims to explain both the differences and the similarities between different human groups. It also aims to give a reason for both the continuity and the change of societies. Some want to see the variations of societies and cultures as an evolution similar to that of species. When biology tries to answer all the questions that man formulates from a general theory of the living, it becomes a universal science, proposing that the behaviors of the social pass to the biological, something that must be criticized.
\end{abstract}

Keywords: Educational Sciences, Philosophy, Ethics, Anthropology, Human Nature, Ontology, Humanism.

\title{
1. Caracterización de la antropología como ciencia
}

La antropología apunta a un conocimiento global del hombre y abarca el objeto en toda su extensión geográfica e histórica:

Aspira a un conocimiento aplicable al conjunto de la evolución del hombre, desde los homínidos hasta las razas modernas y tiende a conclusiones, positivas o negativas, pero válidas para todas las sociedades humanas, desde la gran ciudad moderna hasta la más pequeña tribu melanesia. (Lévi-Strauss, 1996, p.46) 


\subsection{Situación histórica y conocimiento en antropología}

La antropología se desarrolla en forma plena y autónoma en las postrimerías del siglo XIX y se consolida en la primera mitad de nuestro siglo (Barfield, 2001), teniendo como elemento fundante y que le va a conferir originalidad el trabajo sobre el terreno, en localidades situadas lejos de las metrópolis de donde provenían los antropólogos, va construyendo su objeto de estudio y el recorte de la realidad que le interesa investigar, de acuerdo con los distintos momentos históricos. Sus formulaciones, sus elaboraciones teóricas, son el producto de una situación histórica: el colonialismo, el cual ha sido la condición necesaria de la aparición de la Antropología. Los objetivos del trabajo de campo eran dar a conocer en los términos científicos del momento las realidades coloniales.

Las escuelas antropológicas que dominan la historia de la expansión colonial de los siglos XIX y XX son el evolucionismo y el funcionalismo (Feixa, 1996), y con los elementos surgidos de una y de otra se va a constituir, a configurar el Modelo Antropológico Clásico.

Hacia 1860 la reflexión antropológica toma un nuevo rumbo. Entre 1860 y 1880 aparecen las obras clásicas de Bachofen (Bachofen-Echt \& Bachofen-Echt, 1949) y Tylor (Larsen, 2013). El contenido de estas explica que las sociedades están alineadas según un continuo homógeneo y único, jalonado por cortes: estadios de avance. Toda sociedad se ve reducida en un determinado momento, a un estadio de evolución técnico-económico.

En el siglo XIX se asocia el aporte de la civilización a la valoración de los recursos inexplotados. Ya ha caído en desuso la ideología del buen salvaje y ha sido suplantada por la superioridad de la sociedad civilizada o industrial. Dentro de esta corriente de ideas, a la Antropología le cabe como tarea la descripción, o sea antes de ser destruidas, o bien de las condiciones creadas por la colonización (Boas, 2010). En lugar de intentar grandes cuadros comparativos entre los distintos estadios de evolución, el antropólogo debe ahora permanecer largamente sobre el terreno para comprender la sociedad en su interioridad. 
La antropología, con el funcionalismo, deja de ser el mirador de la civilización ante las costumbres aberrantes. Es el mirador de la sociedad industrial ante la vida auténtica (Aparicio-Gómez, 2021). Para el antropólogo que quiere construir una imagen fiel de la sociedad indígena se impone la necesidad de vivir lejos de los otros blancos, en completa convivencia con indígenas. Vivirá entre ellos como un miembro más de su sociedad. En la Antropología funcionalista el punto de vista comparativo se esfuma y deja lugar a estudios monográficos sobre culturas que contienen lo que es necesario para su comprensión.

\subsection{El modelo antropológico clásico}

Es el conjunto de conceptos con los que se aproxima el antropólogo a su objeto de estudio y a las técnicas que es necesario instrumentar para aprender ese objeto de conocimiento hasta traducirlo en el lenguaje de la ciencia (Castro, 2005). La unicidad del modelo debe ser colocada en función de dos situaciones, la unidad de análisis que tradicionalmente ha tenido el antropólogo (la comunidad nativa) y la situación colonial. A continuación, se analiza el Modelo Antropológico Clásico (MAC) a través de dos de sus dimensiones: la dimensión teórica y la dimensión técnica.

\subsubsection{La dimensión teórica}

Está constituida por una serie de variables que son: la objetividad, la autenticidad, la totalidad, el relativismo cultural, la ahistoricidad, la normatividad, la importancia de lo cualitativo y el comparativismo, la homogeneidad e integración. El Antropólogo pretende ser objetivo pues toda ciencia tiene un nivel de objetividad (Dupré, 2019). De todos los científicos sociales, el antropólogo es el que sostiene una relación más inmediata con el objeto; el sicólogo toma distancia, pero el antropólogo convive con el objeto arriesgando su propia subjetividad en el trabajo con el otro.

El nivel de autenticidad se refiere a la posibilidad de llegar a tener un conocimiento de las relaciones profundas, y no superficiales, de una comunidad; significa que una persona no 
representa a otras personas, sino que se representa a sí misma; que toda persona sigue siendo persona en la instancia de la información que ofrece significa que no es un simple ente abstracto, un ente numérico, sino que representa la autenticidad de sí mismo.

Comparativismo: En el MAC todo conocimiento debe ser referido para su posibilidad de generalización, a otras instituciones de otras formas socioculturales. Toda la tradición antropológica establece siempre el principio de comparatividad para poder establecer generalizaciones, cosa que no hacen otras disciplinas sociales y humanísticas.

La totalidad: El conocimiento en Antropología tiende a ser totalizador (Feixa, 1996), frente a la parcialidad de dimensiones que generalmente toma un historiador o un sociólogo.

La integración es otro de los conceptos que manejan los antropólogos en el MAC. Integración significa un grupo social en equilibrio. Una sociedad donde sus partes están en una relación de equilibrio permanente, donde no exista la incorporación de elementos diferenciales que lo rompan.

El relativismo cultural: es el principio por el cual no se emiten juicios de valor sobre tal o cual cultura (Kottak, 2007). Toda valoración es relativa al sistema cultural de una sociedad.

\subsubsection{La dimensión técnica}

Está íntimamente relacionada con la dimensión teórica. Se refiere al tipo de trabajo que realiza el antropólogo y a la unidad de análisis que emplea. La técnica por excelencia del trabajo de campo antropológico es la observación participante, que implica para poder concretarse, el estar operando con una pequeña unidad de análisis, es decir que al plantearse la observación participante se está dando por implícito lo que se denomina nivel de autenticidad. Porque observación participante implica la coactividad y convivencia con la comunidad (AparicioGómez, 2021), o la unidad alternativa que se proponga estudiar. 


\subsection{La antropología contemporánea y la descolonización}

La descolonización es un hecho histórico global. Se trata de la nueva posición de sociedades constituidas ayer en objeto y que, al reencontrar su soberanía, impugnan en ese enfoque la objetivización que les cupo. Después de la guerra de 1945 y a la luz de las primeras guerras de liberación nacional, la Antropología reencuentra como factor esencial la dominación (Marcos Martínez, 2010). A partir de ese momento, del descubrimiento de la situación colonial, la Antropología está ante el colonialismo. Se aleja del sistema colonial para considerarlo desde el exterior. Por los años 30 se asiste ya a la aparición de obras de antropologías elaboradas por intelectuales africanos, ellos pueden defender la cultura de su país, justificar sus valores y prácticas dominantes, contra las interpretaciones deformantes y a menudo interesadas del europeo. El método de esta Antropología será una revalorización de lo vivido, de los valores profundos, es decir, de la cultura nacional tal como aparece a quienes la construyen y la viven. Una comprensión intuitiva del sentido del sistema, por los miembros de ese sistema. En el ámbito de América Latina, la así llamada nueva antropología acompaña a los movimientos indianistas.

\subsection{El ámbito de las realizaciones contemporáneas}

Ahora cabe preguntarse ¿cuál ha sido la temática antropológica en las últimas décadas? ¿Cuáles han sido las aplicaciones del Modelo Antropológico?, que se han demostrado fructíferas para el análisis y explicación de determinados problemas. Hay que referirse a los estudios sobre campesinado, a las investigaciones en Antropología Médica, a la problemática sobre la mujer, a la Antropología Urbana, entre otros (Panyella, 1962).

Los estudios sobre campesinado son de vieja data, tanto en Europa como en América. Las investigaciones sobre campesinado, en las últimas décadas, parten del hecho de que la población rural del mundo contemporáneo constituye un sector dentro de una economía y una política más amplias. 
Los movimientos organizados contestatarios que exigen la liberación de la mujer recurren a los aportes de los antropólogos para validar sus reclamos, para poder captar mejor las relaciones entre los sexos y poder reducir la justificación de la dominación masculina (Rodríguez Castillo, 2018).

La Antropología médica se ha probado productiva y eficaz en sus aportes teóricos. Las temáticas dominantes de esta producción fueron la relación médico-paciente, las enfermedades tradicionales, las terapias nativas, algunos problemas de salud mental como el alcoholismo, los problemas nutricionales y el proceso de embarazo y parto.

\section{La dimensión biológica y la dimensión cultural en la naturaleza humana}

\subsection{Dimensión biológica - dimensión cultural}

La sociedad occidental, caracterizada por un desarrollo espectacular del conocimiento científico, legitima el amanecer de una nueva etapa tecnosocial, tecnolaboral y tecnoindustrial que merece ser estudiada respecto al individuo y la sociedad. En esta mentalidad el individuo no es más que un elemento sometido a las leyes infalibles de la naturaleza y por lo tanto de la ciencia biológica.

Desde una perspectiva diferente, el marxismo define la relación entre la naturaleza y el hombre (Roseberry, 1997). Para Marx la historia del desarrollo cósmico y biológico solo constituye el fundamento científico natural de su concepción de la historia.

\subsection{Sociedad animal - sociedad humana}

\section{Crítica a la etología del instinto de K. Lorenz}

El hombre es un animal y por lo tanto comparte con el resto de los animales una naturaleza biológica y estructura (Zuanon, 2007). No obstante, el hombre es el único animal con cultura. 
La etología es la disciplina que mediante experiencia con animales trata de explicar el comportamiento humano y de aplicar estos resultados a la vida corriente, señala pautas para entender el comportamiento humano, en tanto movido por instintos, como en el resto del mundo animal.

El comportamiento animal se sitúa en dos niveles. Por una parte, el comportamiento como producto de condicionamientos innatos y un aprendizaje espontáneo, que es imitación del otro. Tanto uno como otro permiten al individuo manejarse en situaciones normales. El segundo nivel está dado por la habilidad de un elemental pensamiento práctico.

La diferencia entre la sociedad animal y la humana está en que en ésta última la organización social no está fijada fisiológicamente. Debemos afirmar también, que no existe diferencia de inteligencia desde el punto de vista de la diferenciación de sexos. El hombre es el único que tiene conciencia de sí, puede identificarse con el otro y controlar, en ese proceso de identificación, su propia reacción.

\section{Lenguaje humano}

Aquello que caracteriza al lenguaje humano es la combinación que logra con sus elementos (Aguilera Portales, 2002). Las características que lo hacen único son las siguientes: por un lado, la arbitrariedad del signo lingüístico y por otro, la posibilidad de revestir combinaciones con significantes arbitrarios. Esto significa la presencia de estructuras enunciativas o la construcción gramatical y por último la doble articulación del lenguaje.

La relación entre lenguaje y pensamiento ha producido las siguientes orientaciones principales: en primer lugar, aquella que expresa que el pensamiento depende del lenguaje, la segunda orientación que el lenguaje depende del pensamiento, la tercera que pensamiento y lenguaje forman una unidad dialéctica y en ciertos momentos entran en contradicción, otra orientación defiende la especificidad del lenguaje y su independencia del resto de las funciones mentales. 


\subsection{Proceso de Hominización}

Actualmente se puede decir, con total certeza, que el antepasado del hombre es un primate que hace aproximadamente 20 millones de años se separa del grupo de los monos antropomorfos (Morin, 2012). Según la teoría tradicional, el hombre moderno evolucionó a partir de un tipo no especializado de hombre neandertaloide, en una vasta región que abarca la Europa oriental y el Asia occidental.

Algunos antropólogos aceptan la idea de que las transformaciones del medio y del clima desempeñaron un papel importante en la evolución física y cultural del hombre que habitaba regiones de climas rigurosos (Marconi \& Presotto, 2010). Hay otros que sostienen que la evolución física estuvo determinada por la cultura más que por el medio.

\subsection{Raza y racismo}

El racismo o prejuicio racial es una forma patente de barbarie, cuyas manifestaciones renovadas de opresión y estrategias, que se renuevan constantemente en todo el mundo, son temas de atención permanente. El racismo como teoría seudocientífica es reciente en la historia de la humanidad (Lévi-Strauss, 2010). Surge como teoría recién en el siglo XIX.

Al aproximarnos al siglo XIX, las diferencias entre los grupos fueron atribuidas cada vez más a diferencias raciales. Europa, ante la revolución Industrial, se ve impulsada a la búsqueda de nuevos mercados y renovadas formas de explotación. La necesidad de justificar las políticas de dominación para la expansión colonial necesitó de la racionalidad científica: una explicación racional de la inferioridad de las razas no blancas. Y la teoría que ofreció un marco teórico adecuado a la ideología racista fue la teoría de la evolución de Darwin, que junto al descubrimiento de gran cantidad de restos fósiles y el progreso de los estudios geológicos, ofrecieron una interpretación total de la historia biológica. 
El prejuicio racial resulta siendo un conjunto de sentimientos, juicios y de actitudes que provocan, al menos, favorecen $\mathrm{y}$ en ocasiones simplemente justifican medidas de discriminación (Bourguignon et al., 1980) El prejuicio cultural establece que las desigualdades están dadas por las pautas culturales diferentes. Fue el criterio más usual desde la antigüedad para justificar el esclavismo en la mayoría de los casos.

\subsection{Raza y Biología}

El concepto moderno de raza, fundado en hechos reconocidos y en la teoría de la herencia, desecha para siempre, y definitivamente, el antiguo concepto según el cual existían diferencias fijas y absolutas entre las razas humanas y, por consiguiente, una jerarquización en razas superiores e inferiores. Hay una sola raza humana, la del Homo Sapiens (Castro, 2005). Descendiente de un tronco común, y por tanto las razas son divisiones de esa especie. La especie es una entidad cerrada y las razas son entidades abiertas.

La herencia biológica queda reducida a la transmisión de ciertos caracteres a través del óvulo y el espermatozoide. Esta herencia es la transmisión de ciertas posibilidades que pueden o no manifestarse, según estén dadas las condiciones para ello. Los genes están unidos entre sí, agrupados en los cromosomas y en cada especie el número de cromosomas es constante. Estos genes no son modificados por los demás genes con los que se asocia, sino que la aparición de nuevos genes es un proceso que se conoce como mutación. En muchos casos pueden ser inducidas las mutaciones por agentes externos. Los genes como elementos transmisores de ciertas particularidades, en el proceso de herencia, no son diferentes en las diversas poblaciones humanas y la manifestación o no de esas posibilidades está más en el medio que en ese patrimonio genético. Por lo tanto, un individuo es más un producto del proceso de socialización que de su herencia biológica.

El conjunto de factores más importantes que han determinado las diferencias entre los hombres, y que llevaron a su división en razas son: las mutaciones, la selección natural, las fluctuaciones o accidentes genéticos, y las migraciones y cruzamientos. 


\subsection{Raza y psicología}

En toda sociedad existen individuos marginados. Las pautas culturales de cada individuo pueden determinar su actitud general. La pobreza y sus consecuencias, como la desnutrición, la falta de educación, el lenguaje empleado, son factores que deben considerarse (Giddens, 2000). Es importante también los efectos de las diferencias ambientales como el aislamiento de ciertos grupos y su dificultad para incorporarse a la vida social.

El estudio de Klineberg sobre los test que realizó demuestra hasta la evidencia que no hay ninguna prueba de la existencia de diferencias innatas de inteligencia debidas a la raza (Klineberg \& Klineberg, 2011); que son las condiciones del ambiente social y educativo las que explican las diferencias comprobadas y que a medida que las posibilidades ofrecidas por el ambiente a los diferentes grupos raciales o étnicos tienden a ser las mismas las diferencias observadas desaparecen.

\section{Conclusión}

La especie humana está limitada por su fundamento biológico como el resto del mundo viviente, pero es la única especie que al transformar la naturaleza para sobrevivir crea leyes que la determinan históricamente. La vida biológica de la especie humana sólo resulta posible a raíz de la producción de la vida social. El hombre es el único animal con cultura.

\section{Referencias}

Aparicio-Gómez, W.-O., Aparicio-Gómez, C.-A., \& Hernández Niño, J. F. (2021). El aprendizaje móvil (m-learning) como herramienta formativa para la empresa. Revista Internacional de Pedagogía e Innovación Educativa, 1(1), 69-102. https://doi.org/10.51660/ripie.v1i1.27 
Aguilera Portales, R. (2002). El problema del etnocentrismo en el debate antropológico entre Clifford Geertz, Richard Rorty y Lévi-Strauss. Gazeta de Antropología.

Bachofen-Echt, A., \& Bachofen-Echt, A. (1949). Bernstein. In Der Bernstein und Seine Einschlüsse. https://doi.org/10.1007/978-3-7091-2303-4_3

Barfield, T. (2001). Diccionario de antropología. Bellaterra.

Boas, F. (2010). Cuestiones Fundamentales De Antropología Cultural. Accident; Analysis and Prevention.

Bourguignon, E., Bastide, R., \& Sebba, H. (1980). The African Religions of Brazil: Toward a Sociology of the Interpenetration of Civilizations. The Journal of American Folklore. https://doi.org/10.2307/539887

Castro, C. (2005). Evolucionismo Cultural. Notes.

Dupré, J. (2019). La naturaleza humana. In El legado de Darwin. https://doi.org/10.2307/j.ctvndv61v.9

Feixa, C. (1996). Antropología de las edades. Ensayos de Antropología Cultural. Homenaje a Claudio Esteva-Fabregat. J. Prat \& A. Martínez (Eds.).

Giddens, A. (2000). Etnicidad y raza. Alianza Editorial.

Klineberg, O., \& Klineberg, O. (2011). Background and history. In Social psychology. https://doi.org/10.1037/13603-001

Kottak, C. P. (2007). Introducción a la antropología cultural. GAAP Editorial, Madrid. 
Larsen, T. (2013). E.B. tylor, religion and anthropology. British Journal for the History of Science. https://doi.org/10.1017/S0007087412000039

Lévi-Strauss, C. (1996). Race et histoire. In Race et Culture.

Lévi-Strauss, C. (2010). Raza y cultura. Lecturas de Antropología Social y Cultural.

Marconi, M. de A., \& Presotto, Z. M. N. (2010). Antropologia: Uma Introdução. Editora Atlas.

Marcos Martínez, A. (2010). Filosofía de la naturaleza humana. Eikasia: Revista de Filosofía.

Morin, E. (2012). El Método 5: La humanidad de la humanidad. La identidad humana. In Multidiversadidad Mundo Real.

Panyella, A. (1962). Antropología cultural. Boletín Del Seminario de Estudios de Arte y Arqueología: BSAA.

Rodríguez Castillo, L. (2018). Sobre la naturaleza humana. Pyf. https://doi.org/10.22201/cimsur.18704115e.2018.25.360

Roseberry, W. (1997). Marx and anthropology. Annual Review of Anthropology. https://doi.org/10.1146/annurev.anthro.26.1.25

Zuanon, Á. C. A. (2007). Instinto, etologia e a teoria de Konrad Lorenz. Ciência \& Educação (Bauru). https://doi.org/10.1590/s1516-73132007000300005 
REVISTA INTERNACIONAL DE FILOSOFÍA TEÓRICA Y PRÁCTICA 